\title{
A RÁdIO COMUNITÁria COMO AÇÃo INTEGRADA DE PROMOÇÃO DE CIDADANIA E EDUCAÇÃO AMBIENTAL NA COMUNIDADE QUILOMBOLA DE BOM JARDIM DA PRATA (MINAS GERAIS)
}

Kasandra Isabella Helouise Mingoti Poague ${ }^{1}$ - poaguek@ gmail.com Universidade Federal de Minas Gerais

Fernanda Freire dos Santos ${ }^{2}$ - fernandafstos@hotmail.com Universidade Federal de Minas Gerais

Júlia Chaves Silva Nunes ${ }^{3}$ - juliachaves.nunes@ gmail.com Universidade Federal de Minas Gerais

Emmanuelle Machado Maia Nogueira Lima ${ }^{4}$ - e.maialima@gmail.com Universidade Federal de Minas Gerais Izabelle Vieira de Ávila Matos5 - izabellevam@gmail.com Universidade Federal de Minas Gerais

Daniel Salim6 - danielhcsalim@ gmail.com

Universidade Federal de Minas Gerais

Valter Lúcio de Pádua ${ }^{7}$ - valter@ desa.ufmg.br

Universidade Federal de Minas Gerais 


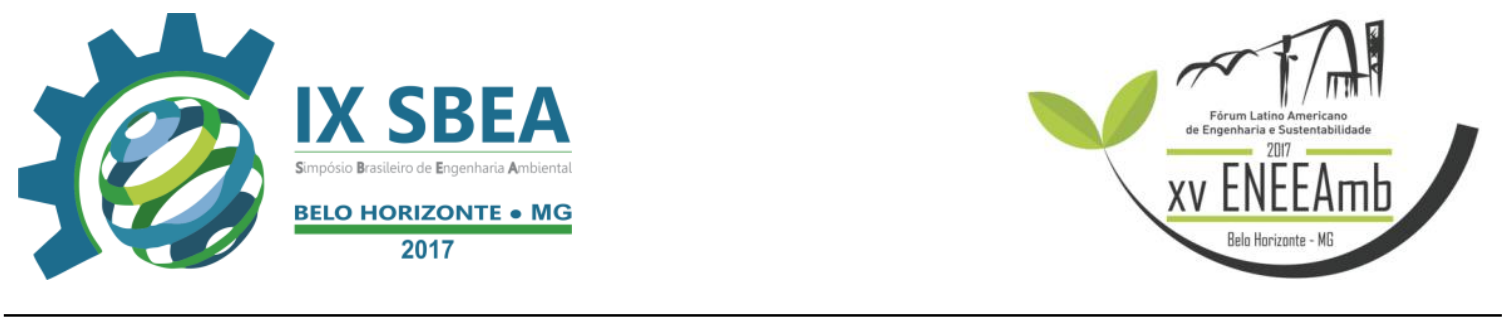

\section{RESUMO}

O presente trabalho apresenta o potencial da hipermídia radiofônica como estratégia educativa no campo da educação ambiental a partir de um estudo de caso aplicado em comunidades quilombolas circundantes ao município de São Francisco (MG). Por três dias, foram veiculados pela rádio comunitária Beira Rio FM 104.9 localizada em uma das comunidades, programas ao vivo articulados em quadros de forma a conciliar a discussão de questões ambientais mais proeminentes nestas com temas cotidianos, a fim de que de se tornassem mais interessantes e lúdicos aos ouvintes. $\mathrm{O}$ engajamento da população das comunidades com os quadros do programa evidencia a grande competência que a mídia rádio possui no alcance e capacidade de formação das pessoas, em se tratando de comunidades quilombolas, seja levando estas a agirem de acordo com os pressupostos de ecologia e cidadania como também no seu auto reconhecimento como um grupo étnico-social, profundamente vinculado ao seu território e a resistência a opressão histórica escravista, dotada de direitos econômicos, sociais e culturais.

Palavras-chave: Educação Ambiental, rádio, quilombolas.

\section{INTRODUÇÃO/OBJETIVO}

Cerca de 80 mil famílias vivendo nas 2917 comunidades de remanescentes de quilombos reconhecidas oficialmente pelo Estado brasileiro (BRASIL, 2013), vivem em condições precárias no tocante ao acesso a água potável, coleta e destinação adequada de resíduos sólidos e esgotamento sanitário, conforme dados das famílias quilombolas inseridas no Cadastro Único para Programas Sociais do Governo Federal (CadÚnico) (Tabela 1). 
Tabela 1 - Situação do Domicílio Quilombola de 2012 a 2014.

\begin{tabular}{|c|c|c|c|}
\hline \multicolumn{4}{|c|}{ Situação do Domicílio Quilombola } \\
\hline & jul/12 & jan/13 & set/14 \\
\hline Abastecimento & $\begin{array}{l}\text { 62\% não possui água } \\
\text { canalizada }\end{array}$ & $\begin{array}{l}\text { 55,21\% não possui } \\
\text { água canalizada }\end{array}$ & $\begin{array}{c}\text { 34,6\% é abastecida } \\
\text { pela rede geral de } \\
\text { distribuição }\end{array}$ \\
\hline $\begin{array}{c}\text { Posse de } \\
\text { banheiro/sanitário }\end{array}$ & $\begin{array}{c}36 \% \text { não possui banheiro } \\
\text { ou sanitário }\end{array}$ & $\begin{array}{l}\text { 33,06\% não possui } \\
\text { banheiro ou sanitário. }\end{array}$ & - \\
\hline Saneamento & $\begin{array}{c}\text { 76\% não possui } \\
\text { saneamento adequado } \\
\text { (28\% possui esgoto a céu } \\
\text { aberto e } 48 \% \text { fossa } \\
\text { rudimentar) }\end{array}$ & $\begin{array}{l}54,07 \% \text { não possui } \\
\text { saneamento adequado } \\
(15,07 \% \text { possui } \\
\text { esgoto a céu aberto e } \\
39 \% \\
\text { fossa rudimentar) }\end{array}$ & $\begin{array}{l}\text { 68,9\% não possui } \\
\text { saneamento } \\
\text { adequado (9,9\% } \\
\text { possui esgoto a céu } \\
\text { aberto e 59\% } \\
\text { fossa rudimentar) }\end{array}$ \\
\hline $\begin{array}{l}\text { Destinação de } \\
\text { resíduos }\end{array}$ & $\begin{array}{l}58 \% \text { queima ou enterra o } \\
\text { lixo no território; e } \\
\text { apenas } 20 \% \text { possui coleta } \\
\text { adequada }\end{array}$ & $\begin{array}{l}57,98 \% \text { queima ou } \\
\text { enterra o lixo no } \\
\text { território; e apenas } \\
\text { 21,19\% possui coleta } \\
\text { adequada }\end{array}$ & $\begin{array}{c}26,9 \% \text { possui coleta } \\
\text { de lixo }\end{array}$ \\
\hline
\end{tabular}

Fonte: BRASIL, 2013; BRASIL, 2014a.

Em se tratando de comunidades quilombolas, assegurar o direito ao saneamento, e como consequência indireta, a saúde, é um marco da luta para o estabelecimento de padrões de equidade étnico-racial, visto que existe uma dívida histórica com a população negra no âmbito do saneamento desde a época colonial com os famosos escravos "tigres", e a saúde da população negra ainda persiste sob um quadro de desigualdades ao longo da história (VIEIRA E MONTEIRO, 2013).

Segundo a Organização Mundial de Saúde (OMS), saneamento é o controle de todos os fatores do meio físico do homem, que exercem ou podem exercer efeitos nocivos sobre o bem estar físico, mental e social. Comumente, a partir desta definição, entende- 


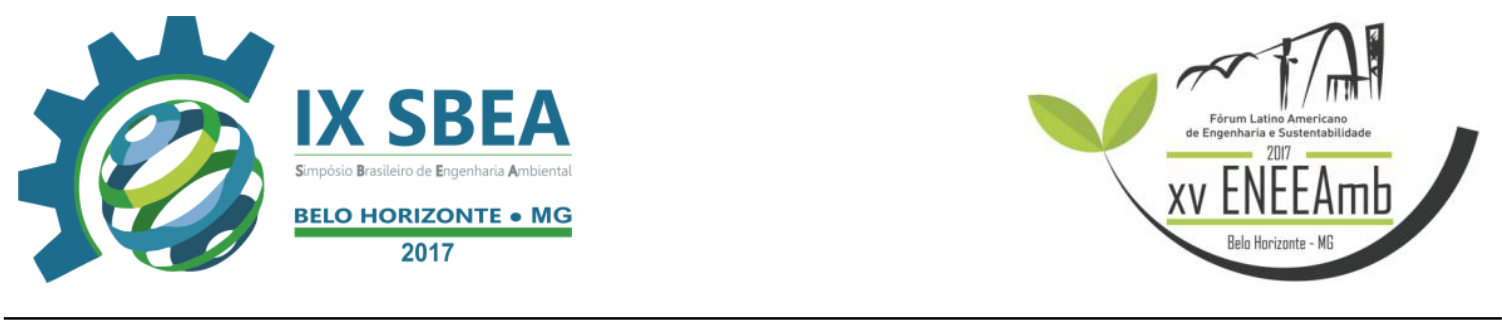

se de maneira equivocada, que as ações de saneamento consistem apenas na intervenção dos fatores do meio físico, interpretado como infraestrutura do ambiente. Olaerts (2013) ressalva que, restringir as ações de saneamento básico somente como medidas de infraestrutura, desconsidera a estreita relação entre saneamento e saúde pública e exclui os determinantes socioambientais (fatores ambientais, econômicos, culturais, étnicos/raciais, psicológicos e comportamentais) que influenciam na ocorrência de problemas de saúde pública.

O próprio Plano Nacional de Saneamento Básico (2014b) reconhece que apenas medidas estruturais, ou seja, os tradicionais investimentos em obras e intervenções físicas com intuito de suprir o déficit de cobertura pelos serviços de saneamento básico, não são por si só, suficientes para garantir e perpetuar um adequado acesso da população a estes serviços.

Referindo-se a comunidades quilombolas, a cultura e as tradições próprias desempenham um relevante papel na sustentabilidade dos serviços de saneamento e saúde pública. Apesar da ausência de condições sanitárias adequadas na comunidade de Caiana dos Crioulos (Paraná), não foram descritas doenças e sintomas como verminoses e diarreias, justificado pelo alto índice de acesso aos meios de comunicação como rádio, televisão e outros veículos aliado ao uso da medicina tradicional (SILVA, 2007). Amorim (2013) destaca que no remanescente de quilombos Boqueirão (Bahia), ao contrário do que se esperava devido aos baixos níveis de escolaridade da população, precárias condições das residências, qualidade insatisfatória das instalações sanitárias e baixas condições socioeconômicas da população ativa, não foi encontrado uma alta prevalência de parasitoses intestinais, situação essa atribuída ao uso popular de plantas medicinais para tratamento de doenças e manutenção da saúde.

Estes resultados indicam que os programas de melhoria de infraestrutura de saneamento em comunidades rurais só se mostrarão efetivos com um adequado trabalho de educação sanitária em conjunto, garantindo o correto acesso às informações sobre uso adequados dos sistemas sanitários, medidas preventivas e curativas, e disseminação de práticas de higiene, sendo preservadas e valorizadas as características culturais da população, posto que: “educação ambiental e meio ambiente não podem ser vistos de 


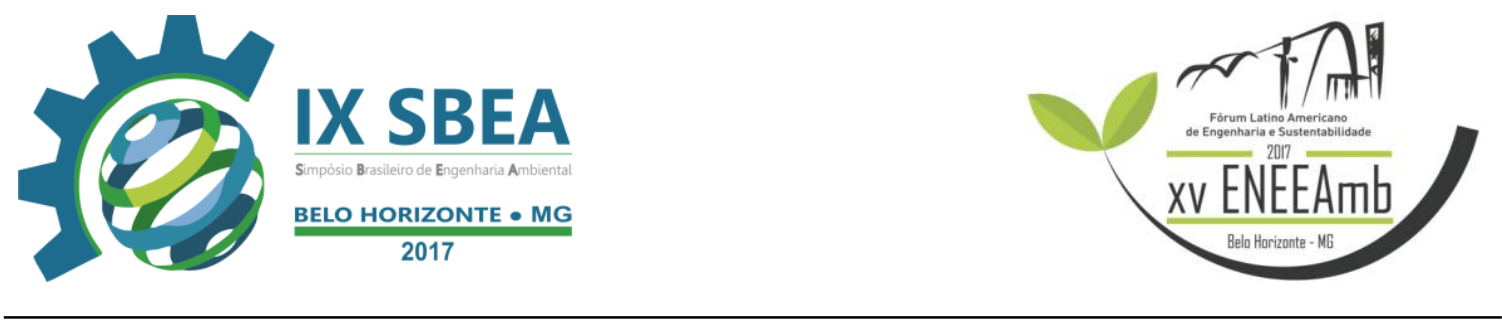

maneira isolada das relações sociais que transpassam suas ações" (JONHANSEN et al., 2011).

A implantação de rádios comunitárias em comunidades quilombolas é uma das ações do Programa Brasil Quilombola e da Agenda Social Quilombola no eixo de promoção de direitos e cidadania, o qual é definido como: "fomento de iniciativas de garantia de direitos promovidas por diferentes órgãos públicos e organizações da sociedade civil, estimulando a participação ativa dos representantes quilombolas nos espaços coletivos de controle e participação social, como os conselhos e fóruns locais e nacionais de políticas públicas, de modo a promover o acesso das comunidades ao conjunto das ações definidas pelo governo e seu envolvimento no monitoramento daquelas que são implementadas em cada município onde houver comunidades remanescentes de quilombos.” (BRASIL, 2013).

A comunicação comunitária se constituiu como espaço de democratização da comunicação, exercício da cidadania e fortalecimento de identidades culturais (ALMEIDA et al., 2009). Nesse contexto as rádios comunitárias se destacam por serem um meio de comunicação capaz de garantir o direito à voz, incontestável a todos os segmentos sociais, e por perpetuar a importância da comunicação para preservação da memória e identidade cultural das comunidades negras.

O presente trabalho consiste na execução de um programa Radiofônico de Educação Ambiental nas comunidades quilombolas ao redor do município de São Francisco, Minas Gerais.

O programa pretendia abarcar três objetivos: promover a aproximação dos executores do projeto com os moradores das comunidades do entorno, os quais seriam pelas próximas duas semanas entrevistadas sobre as condições sanitárias de suas residências; transmitir aos moradores procedimentos básicos de melhoria de condições de saneamento como fervura e filtragem da água; e promover o auto reconhecimento dos moradores como um grupo étnico-social, profundamente vinculado ao seu território e à resistência à opressão histórica escravista, dotada de direitos econômicos, sociais e culturais. 


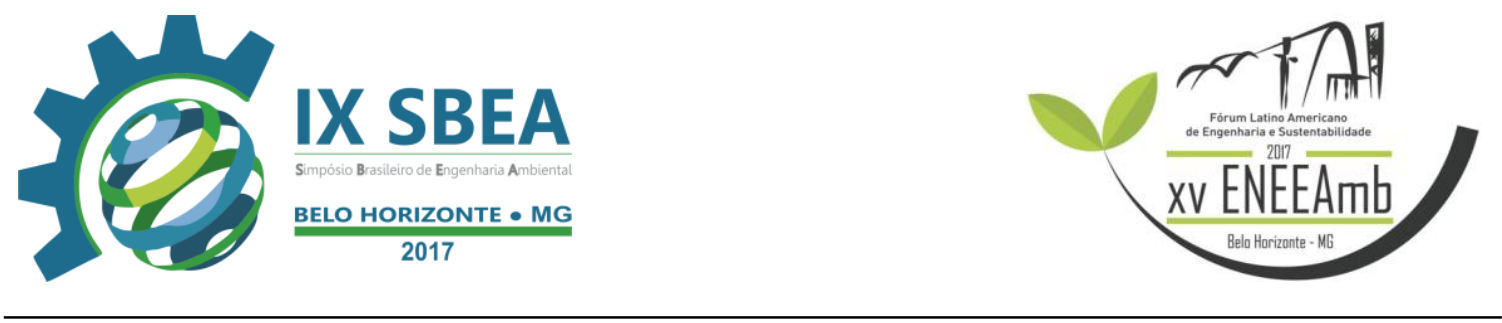

\section{METODOLOGIA}

Característico aos municípios da região norte do estado de Minas Gerais, a cidade de São Francisco é circundada por núcleos populacionais rurais formados por remanescentes de Quilombos, entre eles o território quilombola de Bom Jardim da Prata, que abrange em uma área de 63.168,15 hectares, 630 famílias divididas em 15 localidades (COSTA et al., 2015).

Durante a etapa de diagnóstico e avaliação de condições de saneamento das localidades, por três dias entre as 08 e 09 horas de manhã, o programa ao vivo foi veiculado pela Rádio Comunitária Beira Rio FM 104.9, localizada na comunidade de Bom Jardim da Prata. A região de alcance do sinal da rádio abrange as localidades de Bom Jardim da Prata, Peãozeiro, Benedito Costa, Lagedo e a cidade de São Francisco.

A programação radiofônica foi articulada em quadros de forma a conciliar a discussão das questões ambientais mais precárias nas comunidades com temas cotidianos, a fim de que o programa se tornasse mais interessante e lúdico aos ouvintes. Os referidos quadros são apresentados pela Tabela 2. 


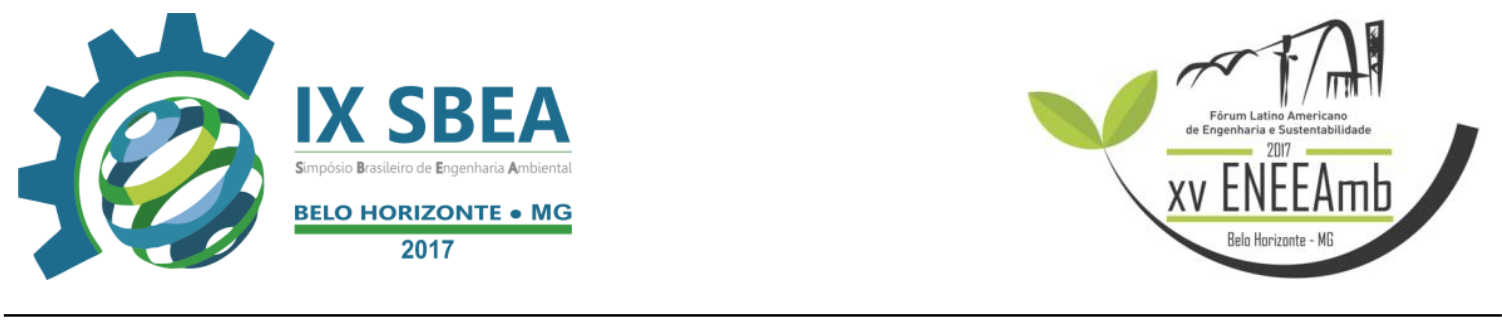

Tabela 2 - Quadros do programa radiofônico e sua breve descrição.

\begin{tabular}{|c|c|}
\hline QUADRO & DESCRIÇÃO \\
\hline RADIONOVELA & $\begin{array}{c}\text { Curtas histórias de } 5 \text { minutos de duração em que Detetive Alberto } \\
\text { Libota resolvia um mistério em São Francisco com seus } \\
\text { conhecimentos sobre saneamento e meio ambiente }\end{array}$ \\
\hline $\begin{array}{l}\text { BATE BOLA- } \\
\text { QUILOMBOLA }\end{array}$ & $\begin{array}{c}\text { Diálogo entre os protagonistas da radionovela sobre o que } \\
\text { significa ser quilombola, seus direitos e dificuldades vivenciados } \\
\text { por moradores de comunidades quilombolas }\end{array}$ \\
\hline $\begin{array}{l}\text { DICAS DE COMO DEIXAR } \\
\text { SUA ÁGUA GOSTOSINHA }\end{array}$ & $\begin{array}{l}\text { Sugestões de soluções de tratamento de água a nível local com } \\
\text { apropriação do conhecimento popular da comunidade; Exemplo: } \\
\text { uso de sementes da árvore encontrada na região, Moringa } \\
\text { Oleifera, como coagulante natural de água }\end{array}$ \\
\hline SORTEIO MAROTO & $\begin{array}{l}\text { Sorteio de uma muda de Moringa à primeira pessoa que ligasse } \\
\text { respondendo corretamente uma pergunta sobre as dicas de como } \\
\text { deixar sua água mais adequada ao consumo humano }\end{array}$ \\
\hline BONDE DA MORINGA & $\begin{array}{c}\text { Paródia da música de sucesso "Cerol na Mão” da banda Bonde do } \\
\text { Tigrão, com o passo a passo de como utilizar a Moringa e seus } \\
\text { benefícios }\end{array}$ \\
\hline
\end{tabular}

Além de músicas intercalando os quadros, as quais os moradores poderiam pedir com dedicatórias, era feito a divulgação e convite das festas das comunidades a fim de promover a união e fortalecimento destas. 

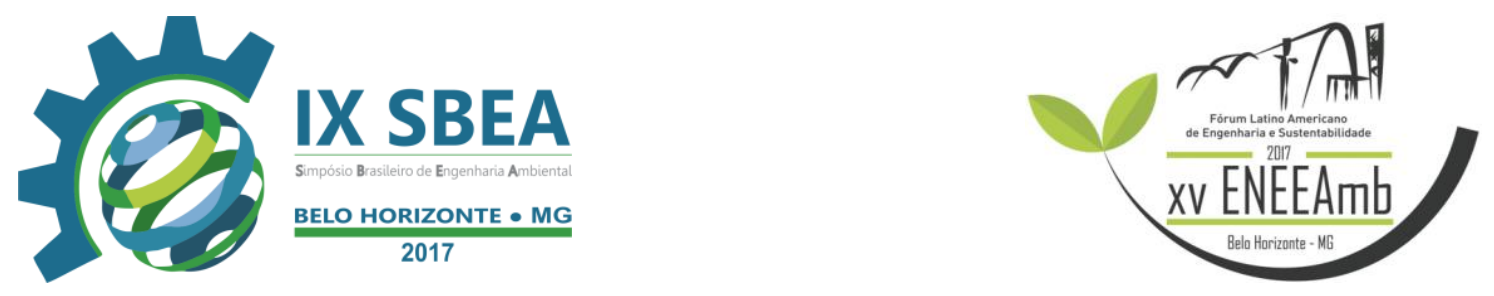

De forma análoga, por vezes os alunos faziam uma breve divulgação do projeto, apresentando seus objetivos e informando a possível visita aos moradores, assim como agradecendo o apoio e atenção.

Devido à grande aderência da população da localidade de Bom Jardim da Prata ao sorteio da muda de Moringa Oleifera, os alunos distribuíram pacotes contendo 10 sementes secas da planta (Figura 1), a todos os moradores da comunidade que responderam o questionário de avaliação das condições de saneamento, incluindo os que participaram do sorteio e que não foram contemplados. Para cada pessoa que recebeu um pacote era explicado como plantar, cultivar e o modo de utilização da semente na água.

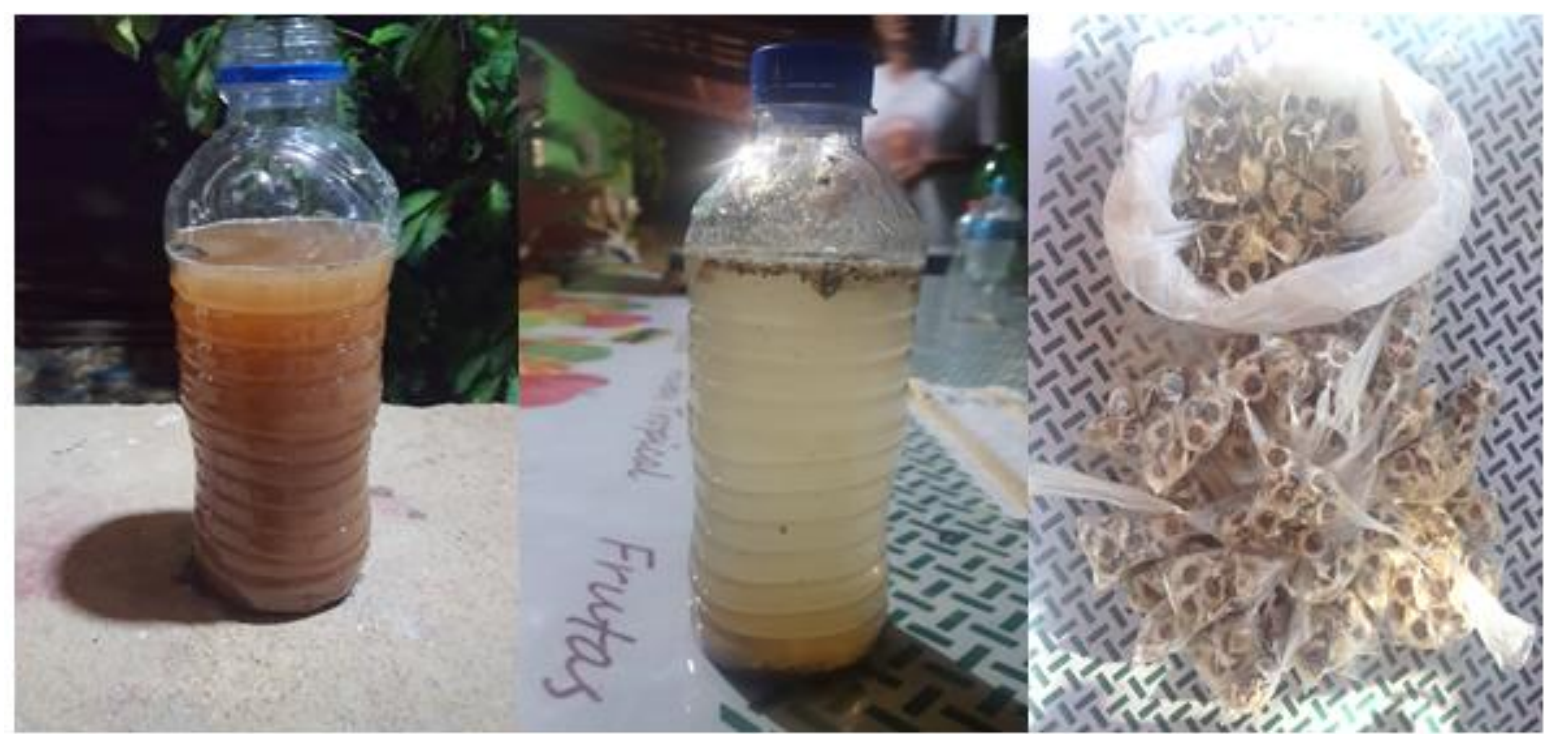

Figura 1: Água antes e após aplicação de sementes de Moringa Oleifera e pacotes com as sementes entregues aos moradores.

\section{RESULTADOS E DISCUSSÃO}

O sucesso e a repercussão do programa foram constatados em diversas instâncias: por meio de pedidos de músicas dedicadas, assim como ligações para participação do sorteio; comentários dos ouvintes durante as visitas para realização dos questionários de saneamento; divulgação do programa de rádio e do projeto na Rádio Nacional de Brasília durante o programa Clayton Aguiar ; indagação dos moradores sobre quando seria a continuidade do programa; constatação do plantio da muda de Moringa Oleifera, durante uma visita feita a casa do ganhador do sorteio, uma semana após a finalização do programa; expectativa dos moradores que receberam os pacotes de sementes quanto ao 


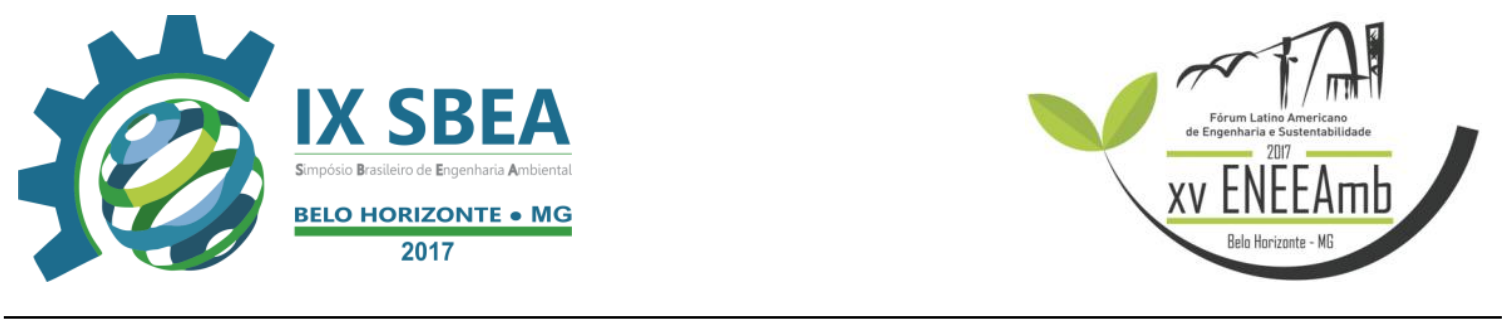

crescimento da árvore. Os programas foram disponibilizados em uma página do site Youtube (São Francisco PROEXT UFMG 2016, 2016).

A despeito da sua curta duração, o programa de rádio revelou-se como essencial para aceitação da população e aderência da realização do diagnóstico de condições de saneamento das comunidades. Em se tratando de comunidades rurais, onde nem todos possuem acesso as mídias - como internet e televisão - e considerando que comunidades quilombolas em sua grande maioria foram excluídas da educação formal (ARRUTI, 2008), a execução do programa em uma rádio comunitária possibilitou uma educação verdadeiramente universal e democrática, com programas elaborados respeitando a cultura e hábitos locais.

\section{CONCLUSÕES/RECOMENDAÇÕES}

Foram perceptíveis pequenas mudanças do comportamento cotidiano dos moradores, que passaram a agir de acordo com os pressupostos de ecologia e cidadania aconselhados durantes os programas. Isso demonstra o grande potencial que a mídia rádio, possui no alcance e capacidade de formação das pessoas dessas comunidades e a necessidade da continuação de programas do mesmo cunho para evitar que os conhecimentos transmitidos sejam esquecidos.

\section{REFERÊNCIAS BIBLIOGRÁFICAS}

ALMEIDA, C. D.; NEULS, G. S.; GUINDANI, J. F.; Rádio Comunitária Quilombo FM: comunidades comunitárias, sujeitos da sua história, cidadãos da sua cidade. In: Mídia Cidadã 2009 - V Conferência Brasileira de Mídia Cidadã, 2009. Guarapuava. Anais. Guarapuava, 2009. p. 835 -851.

AMORIM, M. M; TOMAZI, L; SILVA, R. A. A; GESTINARI, R. S; FIGUEIREDO, T. B. Avaliação das condições habitacionais e de saúde da Comunidade Quilombola Boqueirão, Bahia, Brasil. Bioscience Journal, v. 29, n. 4, p. 1049-1057, 2013.

ARRUTI, J. M. Quilombos. In: PINHO, Osmundo (Org). Raça: Perspectivas Antropológicas. 2 ed. Salvador: ABA/Ed. da Unicamp/EDUFBA, 2008. p. 315- 350. 


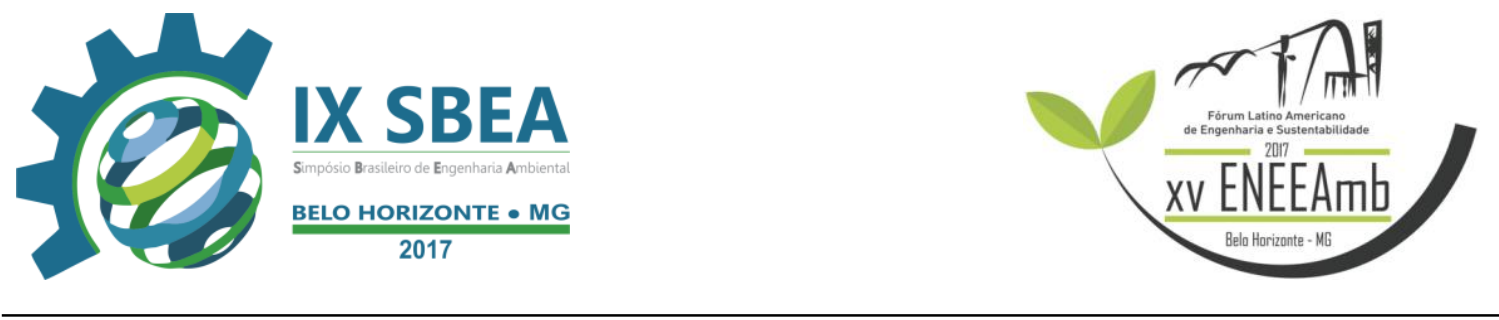

BRASIL. Secretaria Especial de Políticas de Promoção da Igualdade Racial. Programa Brasil Quilombola - Guia de Políticas Públicas Para Comunidades Quilombolas. Brasília, DF, 2013. Disponível em:<http://www.seppir.gov.br/portal-antigo/arquivospdf/guia-pbq>. Acesso em 22 de dez. 2016.

BRASIL. Secretaria Especial de Políticas de Promoção da Igualdade Racial. Programa Brasil Quilombola - Painéis de Monitoramento PQP. Brasília, DF, 2014a. Disponível em: < http://monitoramento.seppir.gov.br/>. Acesso em: 22 dez. 2016.

BRASIL. Ministério das Cidades. Secretaria Nacional de Saneamento Ambiental. Plano Nacional de Saneamento Básico - PLANSAB. Brasília, DF, 2014b. Disponível em: < http://www.cidades.gov.br/images/stories/ArquivosSNSA/PlanSaB/plansab_texto_edita do_para_download.pdf >. Acesso em 22 de dez. 2016.

COSTA, J. B. DE A.; DAYRELL, C. A.; CAA-NM; OLIVEIRA, C. L. DE. Relatório Antropológico de caracterização histórica, econômica, ambiental e sócio-cultural do Quilombo Bom Jardim da Prata - São Francisco (MG). Montes Claros, 2015.

JONHASEN, C. C.; PINTO, J. M. R.; TEIXEIRA, R.; SUDAN, D. C.; RIBEIRO, L. Educação Ambiental nas Ondas da Rádio UPS de Ribeirão Preto. Fórum Ambiental da Alta Paulista, v.07, n.06, p.1012-1018, 2011.

OLAERTS, L. Programa de Saneamento Básico em Assentamento Precário: Estudo de Caso Quilombo Cantão das Lombas. Porto Alegre, 100 p., 2013. Trabalho de Conclusão de Curso (Graduação em Engenharia Ambiental) - Universidade Federal do Rio Grande do Sul.

VIEIRA, A. B. D.; MONTEIRO, P. S. Comunidade quilombola: análise do problema persistente do acesso à saúde, sob o enfoque da Bioética de Intervenção. Saúde em Debate, Rio de Janeiro, v. 37, n. 99, p. 610-618, 2013.

VILELA, D. R. Metodologia participativa na instalação de sistemas de abastecimento e tratamento de água em áreas rurais: o caso da comunidade quilombola de Lagedo. Belo Horizonte, 288 p., 2016. Tese (Doutorado) - Pósgraduação em Saneamento, Meio Ambiente e Recursos Hídricos, Departamento de Engenharia Ambiental e Sanitária - Universidade Federal de Minas Gerais.

São Francisco PROEXT UFMG 2016 - Youtube. Disponível em: <https://www.youtube.com/channel/UCDizhhKMEf4-X287xhUC57w>. Acesso em: 24 de set. de 2016. 